\title{
Major Features of Language Adaptation as a Sign of a Stable Psychological Conditions
}

\author{
Zorjana Kunch ${ }^{1}$, Yaryna Turchyn ${ }^{2}$ \\ Lviv Polytechnic National University, Lviv, Ukraine
}

\begin{abstract}
.
In the context of the Crimea annexation and military actions in the East of Ukraine, increasing the number of first-year students of Lviv Polytechnic coming from bilingual or Russian-speaking families has become a trend. There is a need for research to analyze the psychological state of the student adjusting to the Ukrainian language environment.

Purpose. The study aims to analyze the student's language adaptation as a component of socio-cultural and psychological adaptation.

Design/Methodology Approach. The main diagnostic tool is a survey conducted among first year students.

Results. The data prove that the students' attitude toward the national language is improving. The strategy for students' socio-psychological support is based on various educational factors, particularly the Ukrainian language courses delivery. This is supportive of overcoming disintegration factors, which allows to achieve psychological stability.

Limitations and strengths of the study. The Ukrainian community first encountered the problem of socio-psychological adaptation of IDPs caused by military actions. This does not allow to see the problem under study in dynamics. Due to the consideration of quantitative indicators a wide range of information is analyzed.

Practical/Social Value. The outlined educational factors promote students' love for Ukrainian and a sense of responsibility for their state. Originality/Conclusions. The findings indicate that the language adaptation of young Ukrainians happens smoothly, supported by motivational teaching, interactive learning, students' social participation and involvement in cultural events.
\end{abstract}

Keywords: Crimean and Eastern regions, military actions, social change, national language, student, adjustment to school life, research, teaching Ukrainian, cultural event, social participation.

\section{Introduction}

Under current conditions, due to the migration caused by the annexation of Crimea and the military actions in the Donbass, the issue of socio-cultural and psychological adaptation of internally displaced persons who are far away from their home, finding themselves among strangers, in unusual circumstances is actualized. These people need not only material support and social assistance, but also a certain psychological stability. In this context, the problem of language adaptation is also aggravated, since many Ukrainian citizens who are 
accustomed to using the Russian language in their region move to new locations where they hear the Ukrainian language not only in formal communication situations, but also in everyday life. The number of graduates of secondary schools who come to study in the Western region of Ukraine also grows. Therefore, the enquiry into socio-psychological factors of language adaptation of student youth, accordingly including the search for means of successful inclusion of young people in a new social environment is topical. The article analyzes the attitude of youth to various aspects of language self-identification and suggests ways to promote harmonious introduction of the Ukrainian language into everyday use by young people.

Student youth having moved from most of the Eastern regions of Ukraine, particularly from Donetsk and Luhansk regions, and Crimea, involuntarily became a "hostage" to the obscene language policy of the previous periods, starting from the 1930s, when under the brand of "internationalism" the total Russification of the Ukrainian population was implemented (Dziuba, 1998), and ending with modern legislative acts aimed at protecting and developing languages of national minorities, which however, did not provide proper support to the state Ukrainian language. The social changes caused by the Revolution of Dignity and the hybrid war have contributed to the fact that a significant part of the Ukrainian society still using Russian at all levels, begins to feel the need to communicate in the state language, and introduce it into everyday life and family communication specifically.

The psychological condition of many young men and women is complicated by the fact that in a family there are often conflicting views on the situation in the state. Sometimes the relationship between relatives and friends is complicated by an unfavorable attitude to the desire of one of them to communicate in Ukrainian. This leads to the fact that communication between them becomes more restrained, the frequency of communication decreases, and sometimes communication is completely weakened or even terminated. On the other hand, there is a serious challenge to the Ukrainian community, which can react differently to fellow citizens who do not want to speak Ukrainian, and even to those who seek to communicate in Ukrainian, however, with this being still imperfect.

The research purpose is to conduct a comprehensive analysis of the student's language adaptation as an important component of the socio-cultural adaptation of an individual in modern conditions, as well as to determine measures that a higher educational establishment can offer to improve the effectiveness of this process. The development of a language adaptation strategy will promote overcoming the disintegration factors that may thus arise.

\section{Related Work}

The notion of "adaptation" (from the Latin adaptatio - "adaptation") in the broad sense is widely interpreted as "adaptation of organisms to environmental conditions" (Kunch, 2005 , p. 16). In the scientific literature, it is customary to highlight socio-psychological adaptation, i.e., the process of specific adaptive activity, conditioned by changes in social reality and aimed at optimizing the interaction of an individual with the surrounding social environment in response to changes in the latter. "Socio-psychological adaptation, as rightly noted by Shkoliar, is a process of active adaptation to the requirements of the environment. It should be viewed as an ongoing process of mutual influence of a person and his/her social environment, with its success and adequacy depending upon both individual and psychological features of a person, and on the factors of the environment" (Shkoliar, 2017). The process of adaptation depends upon the socio-psychological needs of 
an individual and the requirements of society. Socio-psychological adaptation "is caused by problem-adaptive situations; actual and potential adaptive barriers that hinder the adaptation of the global human-being to different social situations; and adaptive attitudes arising in the process of the individual interpreting of social being, as well as his/her own roles and sense of life in a particular megasocium" (Sydorenko, 2005).

The authors believe that language adaptation is an aspect of social and psychological adaptation. We adhere to the concept definition, as offered by Tarasiuk, "it is appropriate to understand language adaptation as the process of accumulation of active and passive vocabulary, taking into account the dialect features of the migrant's region of residence, ensuring the transfer of information for the implementation of successful verbal communication" (Tarasiuk, 2011). While being in a foreign language environment, an individual mobilizes his/her internal potential for active interaction with the outside world, demonstrates the ability to adapt to new conditions of existence in the environment, and reveals mobility in his/her interaction with society. The environment in which the adaptation takes place can also contribute to this process, due to which it makes the process occur more smoothly, while exempting it from certain disintegration effects. In the work by Puzyrnyi "Intellectual development and socialization of the individual", the emphasis is placed on the need to strengthen the intellectual education of young people as the precondition for the individual's social adaptation and transformation in an updated society (Puzyrnyi, 2017, pp. 52-56). Based on these studies, we specify the following research objectives:

- To analyze the attitude of Russian-speaking youth to adaptive processes;

- To assess the prospects for youth adaptation in the Ukrainian-speaking environment;

- To determine the value of educational activities to improve language adaptation;

- To propose a strategy to promote adaptive processes.

Methodology. To achieve the goal, a set of techniques was used to study the student's psycho-emotional state and his/her subjective vision of the language behavior features. The main diagnostic tool was a survey conducted among students of the first year of studies at Lviv Polytechnic, and an analysis of its results. The research sample of our study was made up of 171 first-year students of the Institute of Humanities and Social Sciences, among them -34 boys and 137 girls.

\section{Results and Discussion}

Internally displaced persons find themselves in large numbers in Western Ukraine, mainly due to the region remaining the focus of stability. Before the Revolution of Dignity and the Russian Federation military aggression, the contingent of students of Lviv Polytechnic National University had consisted mostly of representatives of Lviv, Ivano-Frankivsk, and Ternopil regions, and to a lesser extent, of incomers from Khmelnytskyi, Volyn', Rivne, and Transcarpathian areas. Lately, the number of the University entrants from the Central and Eastern Ukraine has been growing. This is clearly illustrated by the comparative analysis (Fig. 1): In 2012, 4,613 immigrants from Lviv region, 1,831 people from other Western arears and only 200 representatives of the Central and Eastern regions of Ukraine entered the first year of bachelor's programmes of studies at Lviv Polytechnic. However, with each subsequent year, the situation keeps changing in the direction of reducing the proportion of representatives of the Western Ukraine and increasing the number of incomers from Vinnytsia, Cherkasy, Zhytomyr, Poltava and other remote areas. 


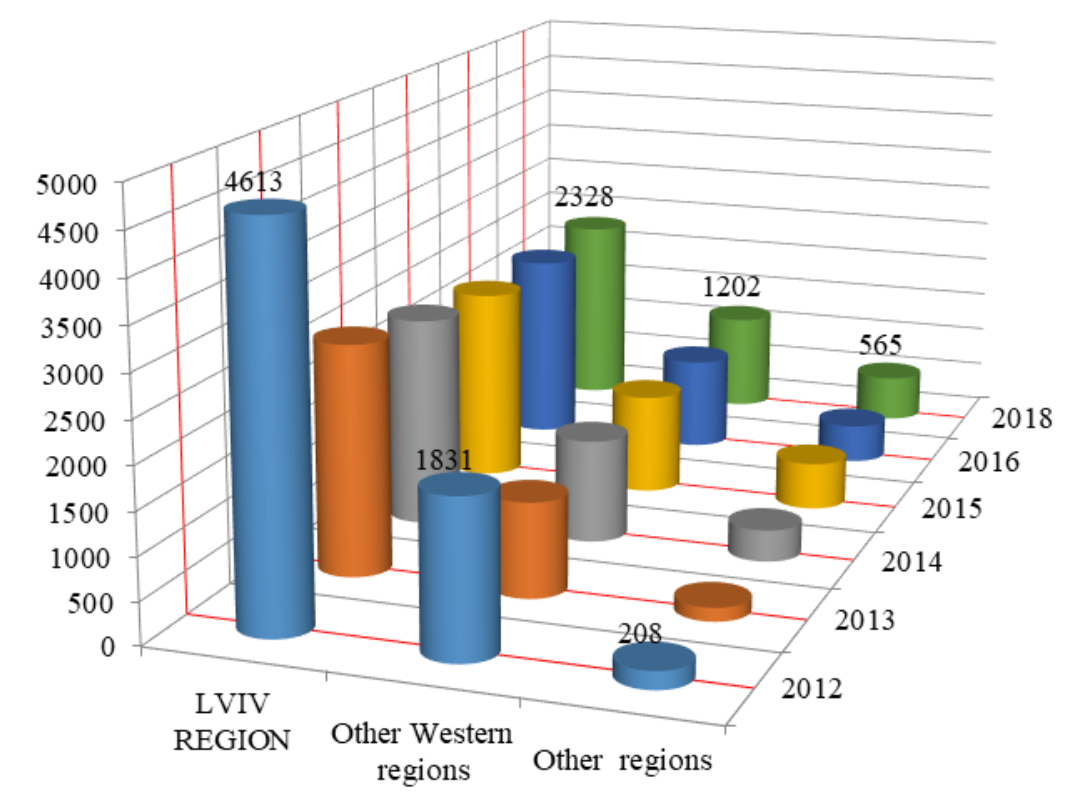

Fig. 1. The contingent of first-year students of Lviv Polytechnic National University (2012-2018)

The above diagram shows the dynamics of change in the number of students. The rapid growth in the number of entrants from the Central and Eastern Ukraine, which falls on 2013-2014, persists in subsequent years.

Migration processes are caused not only by the hybrid war, but also, to a certain extent, by a number of other factors, which may affect the process of language adaptation: firstly, some people from the regions close to the western border choose for themselves studies abroad; secondly, university e-entry, as introduced a few years ago provided an opportunity for youth migration. Besides, many Lviv residents go to study to educational institutions in the capital, as well as to universities in other various regions of Ukraine. Therefore, the share of Lviv Polytechnic students - those who come from the Western regions of Ukraine tends to decrease.

The following two diagrams (Fig. 2) reveal the dynamics of change in the contingent of first-year students of Lviv Polytechnic and show that the number of people coming from the Eastern and Central regions of Ukraine has grown almost threefold. 

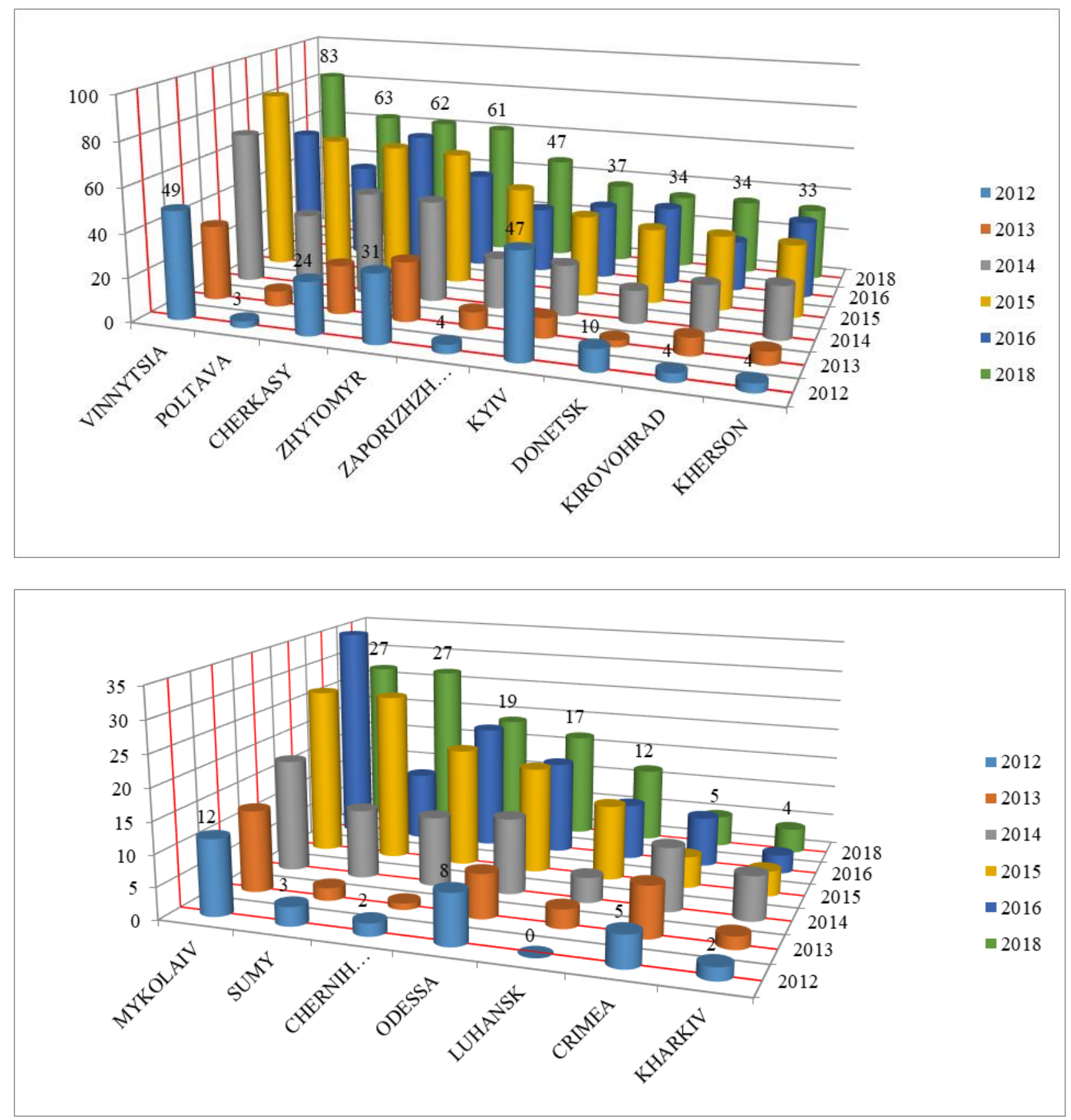

Fig. 2. The contingent of first-year students of Lviv Polytechnic National University (2012-2018)

Reducing the number of first-year students who come from Ukrainian-speaking families and increasing the number of freshmen - those coming from bilingual or Russian-speaking families is an objective process, which has recently acquired stable dynamics. Therefore, it is important to analyze, on the one hand, the impressions, feelings and, in general, the psychological condition of the freshman, who is adapting to the unusual Ukrainian language environment, and, on the other hand, the environment in which the language adaptation of the Russian-speaking student is taking place.

Our questionnaire contained questions in three rubrics: "My Origin", "Education at the University", and "My Feelings". Each rubric was intended to reveal patterns associated with the student's previous experience, the realities of his/her modern life, and the emotions s/he experiences in connection with the language issues. In the first rubric, the following questions were posed: "In what language do you communicate in the family of 
parents?", "In what language did you study at school?", "In what language did you usually communicate with friends in school years?", etc. In the second rubric, which provided for the assessment of the student's modern language practice, the following questions were asked, "In what language do you communicate during the training sessions?", "What language do you use to communicate with your friends in Lviv?", "What language do you use to communicate with friends from your home town (village)?", "What language do you usually use for informal communication with classmates?", "Estimate how often you used the Ukrainian language over the last year", etc. The third rubric - "My feelings" contained the following questions, "What language do you consider to be your native language?", "Do you think that every citizen should know Ukrainian in Ukraine?", "Do you agree that you should communicate in Ukrainian in all official situations?", "Do you feel that your attitude to the Ukrainian language has recently improved?", "In what language do you plan to communicate in your family?", "Would you like the Ukrainian language to sound from the mouth of every Ukrainian in different circumstances of communication?", etc.

An analysis of the previous experience of the survey respondents indicates that communication in the parents' family for 92 incomers from the Lviv, Ivano-Frankivsk, Volyn' and Ternopil regions (conditional first group of respondents) occurs in the Ukrainian language, which is 93\%, although Russian, English, Italian, and Arabic are alternatives. On the other hand, people from the Central and Eastern Ukraine (Chernihiv, Sumy, Odessa, Mykolaiv, Kherson, Zaporizhzhya, Dnipropetrovsk, Donetsk, Cherkasy, Vinnytsia, Kirovohrad, Kyiv, and Zhytomyr regions) (conditional second group of respondents) responded that in the family of their parents they communicate in the following languages: 8 persons - Ukrainian (25.8\%), 12 - Russian only (38.7\%), 5 Ukrainian and Russian (16.1\%), and 5 - Surzhyk (16.1\%). At the same time, the language of instruction at school was Ukrainian for $97.9 \%$ of respondents of the conditional first group, and for $74.2 \%$ of the conditional second group, and only one respondent of the conditional first group attended school with the Russian language of instruction, and in the conditional second group, 4 respondents indicated Russian as the language of instruction (12.9\%). Only $4.2 \%$ of all respondents indicated that they studied at school in two languages (Ukrainian and Russian, or in Transcarpathia, in Ukrainian and Hungarian). Such data testify to the fact that first-year students are fluent in the state language, regardless of the region of Ukraine they are coming from.

When asked "Which language did you usually use in communication with your friends during school years?", all the interviewed from Mykolaiv, Kherson and Odessa regions replied that it was Russian, the same answer was found in 50\% of respondents from Sumy and Chernihiv areas (the other half spoke in two languages - Ukrainian and Russian), and in $62.5 \%$ of representatives of Donetsk, Zaporizhzhya and Dnipropetrovsk regions (another 25\% communicated with school friends in Russian and Ukrainian), and only $12.5 \%$ stated that the

language of communication with their friends was Ukrainian.

Somewhat better is the situation with incomers from Central Ukraine (Kyiv, Zhytomyr, Cherkasy, Kirovohrad, and Vinnytsia regions): $35.7 \%$ of them communicated with friends in school days in Ukrainian, another 35\% - in Surzhyk, and 14.3\% - in Russian, about the same number - in two languages (Ukrainian and Russian). On having moved to a completely Ukrainian-speaking region, in which $95.9 \%$ of peers communicate with friends in Ukrainian, these people found themselves in an unusual language environment.

How has the language environment of Russian speakers changed in the life of respondents of the first year of studies at Lviv Polytechnic? The answer to this question is obtained on 
the basis of the survey analysis in the second rubric. To the question "In which language do you communicate during training sessions?" the answer "Ukrainian" was provided by all respondents (100\%). As for communication with friends in Lviv, specifically $64.5 \%$ use the Ukrainian language, $16.1 \%$ - Ukrainian and Russian, and only Russian $-19.3 \%$ of the representatives from the Southern, Central and Eastern regions. Instead, representatives of the Western regions communicate with their friends in Lviv in Ukrainian - 94.9\%. Young people who moved to Lviv from Russian-speaking regions continue communicating with their friends from their native city or village in Russian (51.6\% of respondents), but some individuals from Odessa, Cherkasy, Vinnytsia, and Kirovohrad regions switched in communication with their school friends to the Ukrainian language $-12,9 \%$.

Quantitative indicators differ in the answers to the question of which language is more often a means of communication in public places (transport, shop, and cafe) and in a hostel, as well as in informal communication with classmates. If in public places people from the Central and Eastern regions predominantly use the Ukrainian language (93.5\%), and only 3.2\% - Russian, and the same number - Ukrainian and Russian, then in a hostel, $68.9 \%$ of them use the Ukrainian language (the rest communicate in Surzhyk $(6.5 \%$ ), Ukrainian and Russian (9.7\%), Russian (12.9\%)), and for informal communication with classmates, $54.8 \%$ of respondents use the Ukrainian language (29\% -Russian, 9.7\% - two languages, and $6.5 \%$ - Surzhyk).

It turns out that official situations compel young people to be more responsive to the choice of the language of communication: it is significant that $6.5 \%$ of students in an informal setting (both in a hostel and when with classmates) use Surzhyk, whereas in public places they do not do this; in informal situations, students use Russian or two languages much more often. To some extent, in informal situations, the choice of the language of communication can be influenced by the language of conversation with the nearest friend (girlfriend) or husband (wife). After all, $41.9 \%$ of respondents indicated that a close friend uses the Russian language ( $38.7 \%$ said so about a husband or wife), $35.5 \%$ Ukrainian (husband or wife - 45.1\%), 16.1\% - two languages (husband or wife - 16.1\%), and $6.5 \%$ - Surzhyk (no answer like that was found with respect to a spouse). That is, in an informal setting, a high percentage of the use of the Russian language or two languages (Ukrainian and Russian) is perhaps caused by the fact that respondents do not communicate in Ukrainian with their closest peers in everyday situations.

It is also important to consider the assessment provided by students as to how often they use the state language in the recent period and whether they use it to a greater or lesser extent. Answers to the question "Estimate how often you use the Ukrainian language in the last year" are distributed the following way: "permanently" - 29.8\%, "more than in other languages" $-58.8 \%$, "only on demand or request" $-6.5 \%$, and "very rarely"- $3.2 \%$. Therefore, we see that less than $10 \%$ of the surveyed students use the Ukrainian language very rarely, or only on a demand or request. At the same time only $9.7 \%$ of students from the Eastern and Central regions of Ukraine stated that in their choice of language of communication in the student years nothing has changed, compared with school years (probably it was the response of those who communicated and communicate in Ukrainian in the parents' family, and also use it for contacts with friends), and more than $90 \%$ answered that recently they communicate more in the Ukrainian language (much more $71.3 \%$ and a bit more $-18.7 \%$ ). This shows that, on having found themselves in the Ukrainian-speaking environment, young men and women are gradually adapting to it and switching to communication in Ukrainian, first only in official situations, and then eventually in an informal setting. 
The questions in the third rubric - "My Feelings" were aimed at revealing the attitude of freshmen to the language and the prospects for the Ukrainian language among the current Russian-speaking citizens of Ukraine. The question "What language do you consider to be your native language? " Ukrainian was named by $97 \%$ of students from the Western region (among the answer options the remaining 3\% were Hungarian, Greek, Arabic, and Azerbaijanian), $85.7 \%$ of people from Central Ukraine (Vinnytsia, Cherkasy, Kyiv, Zhytomyr, and Kirovograd regions), 57.1\% of those from Kherson, Odessa and Mykolaiv regions, and 50\% of students from the Eastern and Northern regions (Donetsk, Zaporizhzhya, Dnipropetrovsk, Sumy, and Chernihiv regions). The Russian language was claimed to be native by $13.6 \%$ of representatives of the last two groups (there was no answer alike among other groups), and only about $4 \%$ of respondents consider the two languages (Ukrainian and Russian) to be native. These data indicate that the vast majority of young Ukrainians find Ukrainian to be their native language.

The answer to the question "Do you think that every citizen should know Ukrainian in Ukraine?" was unanimous: $97.8 \%$ of respondents from the Western regions of Ukraine and $94.4 \%$ of respondents who came from other areas of the country responded affirmatively. Almost all respondents agree that the official language should be spoken in all official situations. A slightly smaller number of respondents, but also an absolute majority of respondents would like the Ukrainian language to sound from the mouth of every Ukrainian under different circumstances of communication: $88.2 \%$ answered "yes", and $11.7 \%$ - "I do not care".

To the question "Do you feel comfortable when you are treated in Ukrainian?" almost all respondents answered affirmatively; in the questionnaire, some even wrote comments like "very", "I am pleased to", "I am so pleased to"; and only two students out of 171 provided the answer "not really". We believe that such a picture attests to the importance of raising awareness and educational work among young people.

Young people are the least protected demographic group, especially in countries with a transitional socio-economic status. Juvenile maximalism, excessive psychological pressure of the need to separate from parents, and personality immaturity are all the problems, which young people are unable to solve on their own; therefore state, social and public institutions must assume certain obligations to provide psychological support to a young citizen (Falkovska, Muzychko, \& Havrylovska, 2017, p. 57). Conditioned by this one of our study objectives was to outline how the student's living environment could contribute to the process of language adaptation. We believe that the major principle of working with Russian-speaking youth is "maintaining the balance between the individual and the environment, and understanding that the environment can become a factor of stress and maladjustment, and a resource in solving problems" (Shkoliar, M., 2017, p. 63).

In our opinion, the strategy of language adaptation of student youth is based on the inextricable unity of action of the three factors - education and training, upbringing, and raising awareness.

A significant factor that creates the maximum effect of psycho-social support, is the availability in the curricula of a bachelor's normative academic course entitled "The Ukrainian language (for professional orientation)", as well as a course on rhetoric, which is offered for students as an elective at the bachelor's level. The outlines of these courses "orient students toward the improvement of school linguistic and stylistic knowledge, the development of skills of the speech culture, more conscious and socially claimed mastery of the literary language norms, the familiarity with the scientific principles of spelling and punctuation and raising the level of literacy - so necessary qualities in every sphere of human activity" (Vozniuk, 2016, p. 51). All freshmen can study these disciplines under 
equal conditions. Thus, students who come from the Russian language environment can improve their knowledge of the Ukrainian language and acquire new language skills under the guidance of an experienced teacher-philologist. "The Ukrainian language (for professional orientation)" course develops various students' general and professional competencies, i.e., to be able to implement the requirements of the Constitution of Ukraine with regard to the statehood status of the Ukrainian language and its application in professional communication; to be able to communicate in writing and orally in the state language, to possess skills of speech culture, to adhere to the norms of the Ukrainian literary language; to logically and correctly express thoughts in the process of professional communication; to be aware of and be able to apply the principles and means of professional communication; to use means of office and business speech; and to use the acquired knowledge for applied purposes. As rightly noted by Ohijenko, "the main nativespeaking duty of every conscious citizen is to work for the sake of increasing the culture of own literary language" (Ohijenko, 1994, p. 12). This thought of the outstanding scholar goes throughout the whole educational process and helps every student in overcoming psychological barriers that s/he can feel under certain circumstances.

The latent impact on persons in adaptation is carried out in the educational process, due to the use of interactive teaching methods in particular. E.g., a business game, in which students exchange thoughts about a certain scientific problem, provides an opportunity for students to learn the way to properly conduct a discussion or business meeting; it is also a platform for applying students' skills of competent communication in the Ukrainian language. A short student's presentation of certain information, in addition to main objectives of this educational event, allows a teacher to exercise control over students' observing orthoepic norms of the Ukrainian literary language and, if necessary, to promote their adjusting. At the same time the student group environment is favorable for the student's language improvement and overcoming certain linguistic failures and imperfections.

However, the task of a teacher-philologist is not limited to the educational component only. In the conditions of the real language situation that has developed in modern Ukraine and the linguistic and psychological instability of students who have found themselves in an unusual language environment, along with the formation of the language competence, it is especially important to promote the development of feelings of responsibility of young people for their own state and understanding that language is the most important attribute of statehood. The teacher is supposed to inspire in young Ukrainians love for their native tongue, to teach them to respect its state status, and to spread the environment of its functioning. To address the problem, various educational and upbringing activities can be effective, namely: cultural trips to theaters, cinemas, and concerts; organization and conduct of language and literary quizzes; involvement of young people in the demonstration of their own talents during various students' festivals, concerts, educational events; and visiting museums, exhibitions and historical sites.

The most appropriate and effective is to involve a young person in personal participation in cultural, upbringing and educational activities, so that s/he feels responsible for delivering certain ideas to the people around him/her in a qualitative way and, accordingly, begins to understand them brighter and more clearly.

The third group of factors of language adaptation is raising awareness. The implementation of raising awareness activities is a function pertinent not only to public organizations and cultural and educational movements. It is also important for the young citizen to reveal for himself/herself the support provided by the state bodies and commercial structures. E.g., cultural and educational television programmes like "The Personality Greatness" on the 
TV "Rada" channel, presentations of book publications during the annual Forum of Publishers in Lviv, etc. are favorable for the student's language adaptation. While partaking in such kinds of events, the young person is getting involved in the corresponding intellectual atmosphere, acquires the feeling that the Ukrainian language environment is fashionable, creative, and harmonious, and this positive attitude prompts $\mathrm{him} /$ her to further assert oneself as a Ukrainian-speaking citizen of Ukraine.

An important prerequisite that promotes the process of adaptation is tolerance (from the Latin "tolerantia" - patience), e.g., tolerance to others' views, thoughts, traditions, and other culture. Young people, who are forced to settle in a new socio-cultural environment, should tolerate the conditions of this environment, and the environment, in its turn, is obliged to support and affirm the intentions of the Russian-speaking person to use the Ukrainian language in all areas.

Here, a significant support for many psychologically unstable persons could be provided based on the Ukrainian legislation (the tenth article of the Constitution of Ukraine, the requirement for a civil servant to pass an examination for fluency in the state language) and political slogans, the ideas proclaimed by the highest state figures (the announcement by the President of Ukraine of the Ukrainian language decade and signing the decree "On urgent measures to strengthen the state status of the Ukrainian language and promote the creation of a common cultural space of Ukraine".

Consequently, the factors of soft impact aimed at ensuring that students learn to love their native language is an effective means of affirming the Ukrainian language in all spheres. In addition, these are precisely the means that do not cause active resistance and aggression, as they are neither radical nor binding. They are aimed at ensuring that a person himself/herself feels the need to communicate in Ukrainian, and also develops and confirms his/her habit of using the state language in all communicative situations.

\section{Limitations of the study}

The Ukrainian community first encountered the problem of social and psychological adaptation of internally displaced persons in connection with the military actions in the East of our country. The short duration of the period during which the socio-psychological adaptation, including language adaptation takes place does not allow us to see the problem under study in dynamics, to reveal certain regularities of the process of language adaptation, which can become a basis for further research.

\section{Strengths of the study:}

This work is based on a specific empirical study, i.e., on the materials of the survey conducted among students of Lviv Polytechnic. The analysis of the specific data obtained as a result on this survey allows us to speak about the reliability of the information incorporated in the scientific analysis. During the work, a wide range of information was analyzed on the thoughts and feelings of young Ukrainians about their speech behavior and attitudes toward language problems. Considering the quantitative indicators that emerged on the basis of the empirical data analysis, we can claim that there is high probability that the scientific hypothesis formulated in this study is confirmed. 


\section{Conclusions (and Future Work)}

The analysis of the results of the survey that we conducted has made it possible to state the following: young Ukrainians born in an independent state are aware that the state language should sound at all the levels: in official business situations, in everyday life, and in the family. So, we believe that almost all respondents answered that they speak Ukrainian fluently or better than other languages. Therefore, $98.9 \%$ of the incomers from the Western region and $93.5 \%$ of those from the Central and Eastern regions of Ukraine having participated in our survey are obviously using the official language in public places. The task of attracting young people to the active use of the Ukrainian language in different informal settings is a pressing duty for state institutions and public formations. Education and training, upbringing and raising awareness are the major factors promoting language adaptation of youth, exercising an effective influence on the upbringing of a sense of patriotismm and love of the native language. This is what assists young men and women in intensifying their own efforts to improve their native language knowledge, and in developing the habit of using the Ukrainian language not only in official situations, but also in everyday life, in an environment of peers, and in the family.

Considering the fact that the attitude of young Ukrainians, especially bilingual and Russian-speaking students, to the state language is improving, we can predict the positive dynamics of this process. Developing a strategy for language adaptation is a problem that requires its immediate solution, as it will contribute to the harmonious introduction of the Ukrainian language into everyday use of persons who previously were in favor of using Russian.

\section{Acknowledgments}

The co-authors are acknowledging the students' enthusiasm and commitment to their involvement in the survey. Real appreciation is expressed to the University top administration for their support of the study.

\section{Authors contributions}

Each of the co-authors of this study equally participated in conducting the survey and analysing its results. The conclusions formulated in this study are the joint elaboration of both authors, who fully support all the theoretical provisions of this work.

\section{Conflict of interest}

No conflict of interests has been observed.

\section{REFERENCES}


Dziuba, I. (1998). Internationalism or Russification? URL: http://izbornyk.org.ua/idzuba/dz04.htm

Falkovska, L.M., Muzychko, L.V., \& Havrylovska, K.P. (2017). "Health" construct in the structure of consciousness of student youth. Physician issues, 7, 57-63.

Kunch, Z. Y. (2005). Universal dictionary of the Ukrainian language. Ternopil: Training book - Bohdan.

Ohijenko, I. (1994). The science on mother tongue duties: Mother tongue catechism for teachers, scripters, clergy, lawyers, students, and a wide range of people. Kyiv: JSC "Oberehy".

Puzyrnyi, V. (2017). Intellectual development and socialization of the individual. Physician issues, 7, 52-56.

Shkoliar, M., (2017). The opportunities of social work in the community in the process of including internally displaced persons into new territorial communities. Physician issues, 7, 63-68.

Sydorenko, S.V. (2005). Social and cultural adaptation: Global aspect. The culture of the peoples of the Black Sea littoral, 68, 163-167.

Tarasiuk, I. (2011). Language adaptation as a kind of socio-cultural adaptation of migrants to a foreign environment. URL: http://oaji.net/articles/2016/15511478884424.pdf

Vozniuk, H.L. (2016). Improving skills of the speech culture in classes of the Ukrainian language (for professional orientation) and rhetoric. In I. S. Popova (Ed.), Ukrainian sense: Scientific collection (pp. 47-56). ISSN 2313-4437: Dnipropetrovsk. 